\title{
The business of genomics
}

Sir - Your excellent editorial regarding commercial genomics was very informative ${ }^{l}$. One statement, however, deserves further comment. William Haseltine, the CEO of Human Genome Sciences, is quoted as stating that there will be little commercial market for presymptomatic testing for genetic disease. I believe that this view is naive and ignores the potential of widespread application of human genomic information and techniques for eugenic purposes. There is a possibility that the techniques developed for automated sequencing and analysis of DNA may eventually allow inexpensive screening of multiple loci for polymorphisms. This information could then be applied to evaluate the probability of developing not only monogenic disorders but also diseases caused or strongly influenced by complex genetic interactions.

There is relatively little risk of widespread eugenic applications in North America or Western Europe where there are strong traditions of individual liberty and considerable concern about eugenics. I suspect the same will be true for countries with predominantly Roman Catholic populations, such as those of Latin America. But what about China, whose "Law of the Peoples' Republic of China on Maternal and Infant Health Care", in force as of 1 June 1995, has a strong eugenic component ${ }^{2-6}$ ? The Chinese government is pursuing what has been termed 'negative eugenics' in an effort to reduce the social burden of caring for the handicapped/disabled and to restrict further population growth. The language of the law is quite broad and includes mental illnesses such as schizophrenia and manicdepressive illness. The Chinese state has a history of eugenically oriented legislation and it appears that an early form of the present legislation has been implemented in at least one Chinese province ${ }^{3}$. Mass screening of populations for alleles that increase the risk of common diseases would not seem to be very practical but more focused screening of individuals with a family history of disorders with a genetic component might be feasible. The practicality of screening will depend to a great extent on the expense of screening measures and this is impossible to judge at this time. Even if relatively expensive, the history of the 20th century provides numerous examples of the tremendous coercive powers of the modern state applied destructively to irrational ends.

A more realistic scenario is the adoption of eugenic practices without mass screening. There are incentives to practice eugenics that make state mandated genetic evaluation uneccessary. The restrictive population policy practiced by the
Chinese state has already encouraged a form of eugenics in which preferred male fetuses are less likely to be aborted. What happens when parents (of any nationality) can ensure that their child is free of a number of genetic traits perceived as undesirable? What about a group of loci/polymorphisms that increase risk of schizophrenia? What happens if a locus is found that significantly influences the risk of homosexual tendencies? I predict that the temptation to ensure a child's optimum genetic 'health' will prove irresistable to many, especially in nations that are struggling to control population growth. Market demand for eugenic services will result inevitably in the provision of those services as less scrupulous commercial vendors respond to demand. Ironically, Huxley's Brave New World may be brought about not by the action of a centralized state pursuing abstract ideals of human normality but by the operations of the marketplace.

\section{Roger L. Albin}

Dept. of Neurology, University of Michigan, Ann Arbor, Michigan 48109, USA

1. Editorial. Nature Genet. 13,1-5(1996)

2. Bobrow M. J Med Genet 32, 409 (1995).

3. Pearson, V. Br. J. Psych. 167, 1-4 (1995)

4. Editorial. Lancet 346, 131 (1995).

5. Editorial. Nature 367, 1-2 (1994)

6. Editorial. Nature 378, 549 (1995) 